\title{
GIS-models work well, but are not enough: Habitat preferences of Lanius collurio at multiple levels and conservation implications
}

\author{
Mattia Brambilla $^{\mathrm{a}, *}$, Fabio Casale ${ }^{\mathrm{a}, \mathrm{b}}$, Valentina Bergero ${ }^{\mathrm{a}}$, G. Matteo Crovetto ${ }^{\mathrm{a}}$, Riccardo Falco ${ }^{\mathrm{a}}$, \\ Irene Negri ${ }^{c}$, Paolo Siccardi ${ }^{a}$, Giuseppe Bogliani ${ }^{c}$ \\ ${ }^{a}$ Fondazione Lombardia per l'Ambiente, Settore Biodiversità e Aree protette, Piazza Diaz 7, I-20123 Milano, Italy \\ ${ }^{\mathrm{b}}$ Università degli Studi dell'Insubria, Unità di Analisi e Gestione delle Risorse Ambientali, Via Dunant 3, I-21100 Varese, Italy \\ ${ }^{\mathrm{C}}$ Università degli Studi di Pavia, Dipartimento di Biologia Animale, Piazza Botta 9, I-27100 Pavia, Italy
}

\section{A R T I C L E I N F O}

\section{Article history:}

Received 11 December 2008

Received in revised form 21 March 2009

Accepted 29 March 2009

Available online 28 April 2009

\section{Keywords:}

Multiscale

Shrike

Predictive model

Habitat mosaic

Model validation

\begin{abstract}
A B S T R A C T
Species conservation largely depends on knowledge of habitat needs of target species. GIS-models are increasingly used to assess habitat preferences and distribution of target species, but their accuracy is constrained by availability of digital data layers. We developed a two-steps approach aiming at showing pros and cons of landscape (GIS)- and site-level habitat models, identifying key habitat factors for conservation of a threatened bird species, the red-backed shrike Lanius collurio. A spatially explicit GIS-model was generated using landscape variables, and a second model at site level was developed using fine-scale variables measured on the ground. The GIS-based model was then extrapolated to the entire region to obtain a map of distribution of suitable habitats. Positive associations between shrike occurrence and both hedgerow length and partial shrub cover were detected at both scales. Shrikes were also positively associated with grassland cover at landscape level and with partial cover of untilled herbaceous vegetation at the finer scale, and negatively affected by lucerne cover. The GIS-model led to an affordable map of predicted habitat suitability which should help conservationists to focus on different local priorities, but was unable to identify effects of untilled and lucerne cover. Site-level model gave fine details for habitat management, but its application elsewhere requires ground-measurements of factors. Combining the multiscale models could indicate more urgent actions at large scales (e.g. maintaining suitable habitats, or improving connectivity among isolated patches) and draw a detailed figure of the most suitable habitat for the species. Shrike occurrence was associated with a higher number of shrub and tree species: the indicator value of the species should ensure general benefits for biodiversity from dedicated management.
\end{abstract}

(c) 2009 Elsevier Ltd. All rights reserved.

\section{Introduction}

The knowledge of distribution, characteristics and spatial arrangement of preferred habitats is essential for the conservation of a species. Habitat models generated using generalized linear modelling techniques can assist in delineating habitat requirements of a species; when habitat factors are available as GIS layers, habitat models can be extrapolated to produce maps displaying the spatial configuration of suitable habitats (Guisan and Zimmermann, 2000). The habitat suitability maps so obtained can be used to facilitate conservation, increment or restoration of critical habitats and have broad use in conservation biology and wildlife management (Manel et al., 1999; Jaberg and Guisan, 2001; Gibson et al., 2004).

GIS variables are usually 'coarse' landscape features which are likely to have no direct physiological relevance for a species' per-

\footnotetext{
* Corresponding author. Tel.: +39 0280616140; fax: +39 0280616180

E-mail address: brambilla.mattia@gmail.com (M. Brambilla).
}

formance, but can act indirectly on causal variables (Guisan and Zimmermann, 2000; Austin, 2002; Gibson et al., 2004), thus being helpful in identifying habitat associations, but likely not detailed as needed for describing fine, territory-scaled habitat preferences of a species. Therefore, although models developed from such coarsegrained landscape (GIS) variables can predict species distribution effectively (Jaberg and Guisan, 2001; Osborne et al., 2001), their accuracy can be improved by the inclusion of more detailed habitat data (Lindenmayer et al., 1999; Manel et al., 1999; Osborne et al., 2001). Given that finer-scaled habitat variables are unlikely to be captured at landscape level (Austin, 2002), the modelling process could involve two steps, whereby a spatially explicit model is first generated using landscape (GIS) variables, and a second model at site level is developed using fine-scale habitat variables measured on the ground (Gibson et al., 2004). Such multiscale approaches for modelling habitats are not new (Hall and Mannan, 1999; Luck, 2002), but studies involving analyses combining both GIS and on-ground variables are rare (Loyn et al., 2001; Gibson et al., 
2004). Because measuring ground variables is money- and timeconsuming, despite the potential power of combining the two above steps, the first one alone is most often used for conservation planning (Gibson et al., 2004), but there are few information about the effectiveness of working only with coarse factors under a GIS option. Here, we investigate similarities and differences between habitat models obtained through GIS- and ground-variables, respectively, explore the potential application of both models, and use the complementary information they provided for deriving conservation implications at regional scale for an endangered bird species.

Breeding habitat plays an essential role for bird species life. Many birds species are currently threatened by unfavourable environmental changes or by habitat destruction or degradation prompted by human activities (Tucker and Evans, 1997), and a case of particular concern is represented by farmland birds (Fuller et al., 1995; Siriwardena et al., 1998; Krebs et al., 1999). This dramatic and widespread decline has been related to agricultural intensification (Tucker and Evans, 1997), especially through loss of ecological heterogeneity (Benton et al., 2003). Also land abandonment, which mainly affects marginal areas and is often indirectly caused by intensification, could negatively affect several bird species (Tucker and Evans, 1997), and particularly Mediterranean ones (Suárez-Seoane et al., 2002).

The red-backed shrike Lanius collurio (Aves: Laniidae), a typical passerine species of Euroasiatic low-intensity farmland landscapes, is one of the species most sensitive to agricultural changes and underwent large declines over most of Europe during the last Century (but with recent slight increase in Belgium, Poland and Romania; BirdLife International, 2004), disappearing almost completely from large areas, and being consequently listed in the Annex I of the Birds Directive (79/409/CEE). The main reason for the decline probably relies on the increased intensification and mechanization of traditional agriculture, which led to unfavourable changes of breeding habitats (Ellenberg, 1986; Maréchal, 1993; Tucker and Heath, 1994; Fornasari et al., 1997; BirdLife International, 2004), but conditions in the African wintering grounds or migratory stop-over areas may also have affected its population status (see e.g. Peach et al., 1991; Saino et al., 2004). Recently, some studies have tried to address habitat determinants of species' occurrence and breeding performance in many areas, including Italy (Brambilla et al., 2007a), but studies in southern Europe (which hosts an important part of the European population; BirdLife International, 2004), are still scarce and most works deal with central or northern Europe (Kuzniak and Tryjanowski, 2000; Vanhinsbergh and Evans, 2002; Karlsson, 2004; Roos and Pärt, 2004; Tryjanowski et al., 2006; Titeux et al., 2007; Golawski and Golawska, 2008).

Lombardy includes portions of both the Alpine and Apennine chains, which at intermediate elevations host key populations of red-backed shrike. Lowland areas in the region have undergone heavy agricultural intensification (generally heavier than in the rest of Italy), resulting in wide extensions of specialized cultivations, often with a single crop occupying tens or hundreds of hectares (especially Zea mays), without marginal features (as hedges, shrub or tree patches). Therefore, conservation of farmland birds in hilly and mountain areas, where changes of agricultural practices have been less dramatic, is a priority for bird conservation in Italy, and especially in Lombardy. At the same time, land abandonment is dramatically reducing open habitats in hilly and mountain portions of the region, thus leading to further unsuitable modification to the breeding habitats of shrikes and other farmland or ecotonal species (e.g. Brambilla and Rubolini, 2009).

Red-backed shrike is one of the most threatened species in Lombardy and is listed among conservation priority by the regional government; although few quantitative data are available, where the current and previous estimates can be compared, the species seems to have dramatically declined, as in Varese (Guenzani and Saporetti, 1988; Gagliardi et al., 2007) and Bergamo (Cairo et al., 2003) provinces.

To obtain a map of habitat suitability and thus of potential distribution, we integrated individual habitat choice with regional distribution through a bottom-up procedure, as the one proposed by Sergio et al. (2004), which is based on the traditional biogeography theory that geographical distribution of a species results from the collective outcome of the adaptive habitat choices of individuals (Sergio et al., 2004). In our first step, we worked with available GIS layers to (i) identify habitat determinants of species' occurrence at the landscape scale by considering red-backed shrike in sample areas representative of the habitat variation within the region; (ii) extrapolate the habitat model to the entire regional surface, to identify the most important areas and main opportunities and problems for the conservation of the species in Lombardy (see Gibson et al. (2004), and Sergio et al. (2004), for theoretical background of this approach). Given the current absence of detailed data on shrike distribution and abundance and the lack of knowledge about ecological needs of the species, such an approach could provide the urgent information needed for conservation planning, which could not be achieved through detailed surveys at regional scale (which are too costly in terms of time and economical effort and the limited timeframe within which unsuitable habitat changes happen does not allow time-consuming analyses) (see Favreau et al., 2006).

The second step involved the definition of finer scale habitat determinants of species occurrence, measuring detailed variables on the ground. For the second step of our work, we selected sites which were both (i) representative of the different ecological situations found in the region, and (ii) easy to access to reduce the large effort required by variables measurement on the ground in the limited available timeframe. The measurement of finer scale variables could provide us with further information and improve our ability in defining conservation implications.

We also carried out a field-testing of validity of both our models over space and time, by carrying out further field work in the successive breeding season.

We tested the possible effects of habitat characteristic on breeding output of the species, by analysing the relationships between breeding performances and variables deemed as important by the fine-scale analysis.

Finally, as the red-backed shrike has been reported as being tied to biodiversity-rich landscapes (Casale et al., 2007), we further explored how its occurrence correlates with other (independent) estimates of biodiversity.

\section{Materials and methods}

\subsection{Study area}

The study area includes the whole territory of the Lombardy region, $\mathrm{N}$ Italy $\left(23,870 \mathrm{~km}^{2}\right)$. Elevation ranges from a few meters above sea level near the eastern part of the Po plain, to $4049 \mathrm{~m}$ a.s.l. of Mount Bernina. Fieldwork was concentrated under $2000 \mathrm{~m}$ a.s.l.

The area could be roughly divided into three main geographical sectors: Alpine and pre-Alpine topography, occupying the northern part of the region; the Po river plain, occupying the central sector (including the main towns); the Apennine part, involving the south-western corner of Lombardy. Many large rivers cross the study area, mainly in a north-south direction, with the exception of the Po river (west-east direction).

Most of the study area is strongly altered by human activities; particularly, the NW portion of the lowland sector (i.e. the central sector) is highly urbanized, with more than $3000 \mathrm{~km}^{2}$ almost uni- 
formly covered by human settlements. On the other hand, the SE portion of the area (still within the lowland sector), is poorly urbanized but intensively cultivated, and appeared as a large and uneven expanse of monocultures (predominantly of Zea mays and other cereals).

In lowland areas, nearly all the relict natural or seminatural landscapes are found along riverine habitats. Low-intensity farming areas occur here and there, embedded in a matrix of intensive agriculture. Conversely, the pre-Alpine and Alpine sector still holds more or less unaltered semi-natural ecosystems. Finally, the Apennine portion of the area (i.e. the southern corner of the region) holds large woodlands and a biodiversity rich agricultural mosaic, probably representing one of the most important low-intensity agricultural landscapes among the few remaining in northern Italy (Bogliani et al., 2003; Brambilla et al., 2008). Both in the Apennines and in the Alpine area (especially in central pre-Alps) there are wide expanses of pastures and grasslands used for livestock grazing and hay production. In both mountain chains, however, livestock rearing with 'traditional' methods is declining, being replaced by intensive rearing in cattle-units in lowlands.

\subsection{Field work and general methods}

When models are built with the aim of being applied to other situations, they have to be used and tested over the whole range of conditions over which inferences using the model may be drawn. Therefore, 10 study areas were selected for territory mapping (see Fig. 1) as representations of different landscapes, elevation and macro-habitats encountered in the region. The largest two (agricultural landscape in Varese province and northern Apennines) were divided into sub-areas. Each study area (or sub-area) was censused by walking at a slow pace, two to five times in the morning (05:00-12:00 h) between 25 May and 1 August 2007. Census-time was slightly postponed with respect to a previous study in a neighbouring region (Brambilla et al., 2007a), because in 2007 migrant birds were noted until 25 May and breeders seem to settle relatively late during the season. We recorded on detailed aerial photographs (scale 1:2000) all the contacts obtained within the areas and the nests we were able to find. Following methods used elsewhere with the species (Brambilla et al., 2007a and references therein), where nests were not found we defined a territory centre as the midpoint of all the records we obtained from a pair (particularly male and female together, singing male, aggressive encounters, pairs showing courtship, copulating or nesting behaviour). Because of the marked territoriality of this species, the use of such records is useful to define territory shape (Karlsson, 2004; Tryjanowski and Golawski, 2004).

Overall, 102 territories were mapped within the 10 study areas. A further 102 random points were generated by means of a GIS procedure over the entire regional surface.

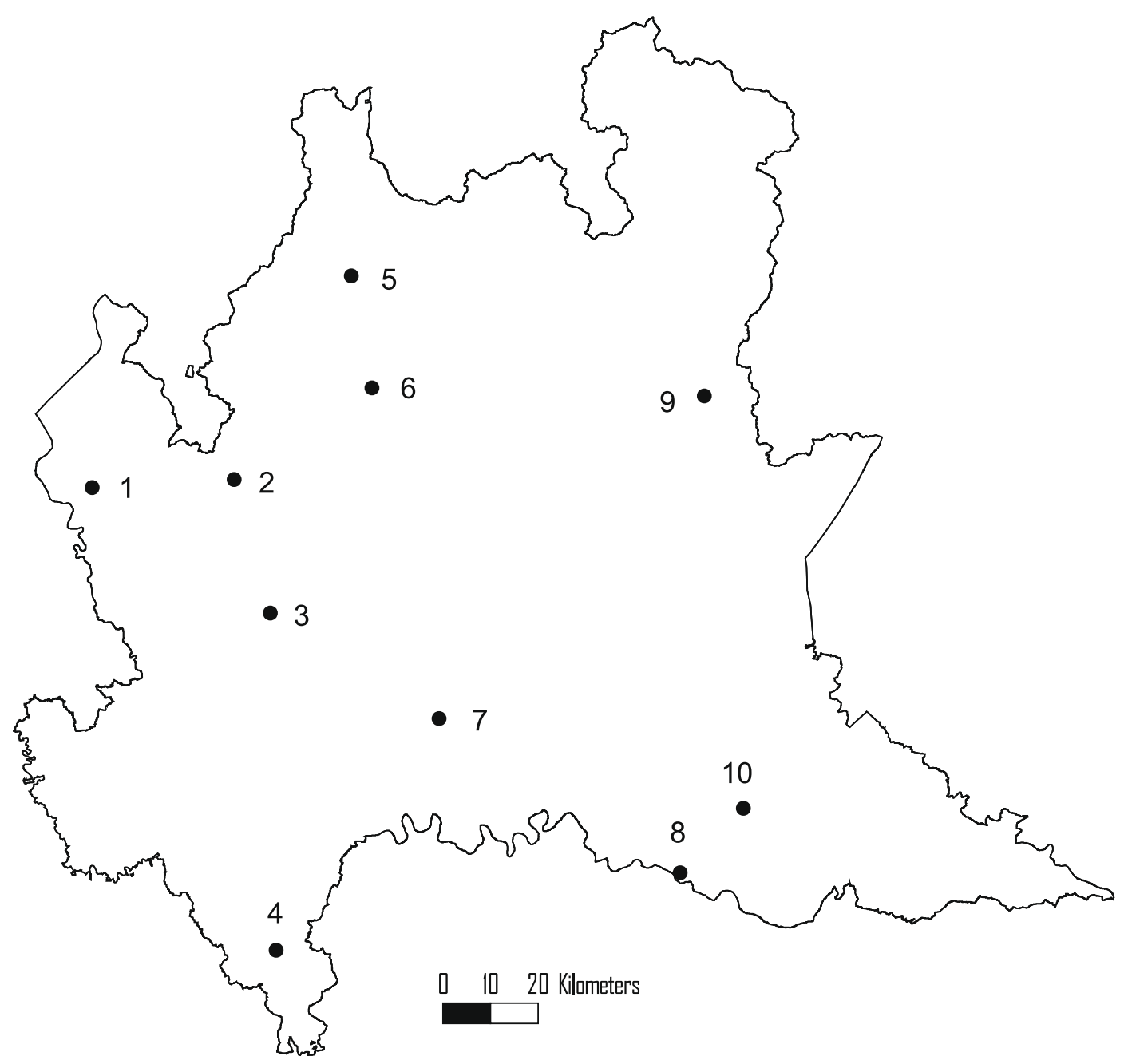

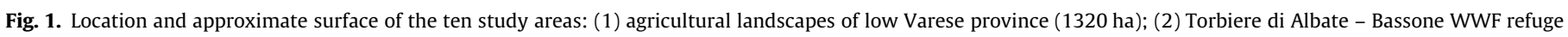

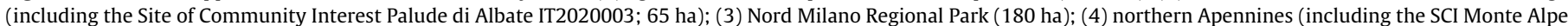

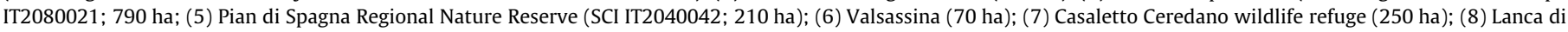
Gerole (SCI IT20A0013; 200 ha); (9) Pascoli di Crocedomini (SCI IT2070006; 12 ha); (10) Le Bine Regional Nature Reserve (SCI IT20A0004; 40 ha). 
Simultaneously, other occurrence data were collected over the whole region, by authors and volunteer observers, outside the 10 study areas.

\subsection{Scale and habitat variables}

Variables were measured within 1-ha plots, set on the basis of territory size in a neighbouring area (Brambilla et al., 2007a) and on the basis of our findings: in Lombardy, 16 territories mapped in 2007 for which most detailed definition of boundaries was available (different positions of birds recorded during several visits) had an average area equal to $1.08 \pm 0.14 \mathrm{SE}$ ha. Finally, the observation of 10 territories in 10 ha (see Section 3) suggested that territories in some cases probably do not exceed $1 \mathrm{ha}$, and adopting larger plots would result in pseudoreplication due to plot overlap between or among neighbouring territories. These are the reasons underlying setting sample units at 1 ha, despite somewhat larger territories were reported for other European countries (e.g. Golawski and Meissner, 2008).

\subsubsection{Step 1: landscape level}

We measured macro-categories of vegetation types in relation to different land-uses. To describe features of the 102 territories and 102 random points, we created 1-ha circle around the nest/ midpoint of observations and around the random points. We quantified the proportional cover within the circle of the following types of land-use and vegetation: waterbodies, arable grassland, perennial crops (orchards, vineyards, poplar plantations), urbanized areas, woodland, grassland and pastures, shrubland, rocky areas (including bare ground and scattered vegetation of rocky or sandy soils); then, the averaged value of elevation (in meters above sea level), orientation (degrees from north) and slope (degrees) for each circle were calculated on Digital Terrain Model (DTM) gridtheme in the GIS; finally, we measured the length of hedges (meters) included within each circle.

The habitat cover and hedge length were estimated on a highdefinition map of land-use (scale 1:10 000; DUSAF, ERSAF - Regione Lombardia).

\subsubsection{Step 2: site-level}

For the measurements of fine-scale variables we were forced to exclude some of the territories and areas used for the first step because of time and accessibility constraints. We only considered territories within the following areas: 'agricultural landscapes of low Varese province' (five territories excluded because of difficult access); 'Torbiere di Albate - Bassone WWF refuge'; 'northern Apennines'; 'Pian di Spagna Regional Nature Reserve' (one territory excluded because of difficult access); 'Valsassina' (see Fig. 1 for location and size of study areas). After the exclusion of the area 'Pascoli di Crocedomini' the mountain areas in the northern half of the region became under-represented, so we included eight additional territories from a more accessible mountain sector ('Triangolo Lariano'; 965 ha), located mid-way between the areas 'Torbiere di Albate - Bassone WWF refuge' and 'Valsassina'. In total, 76 territories were considered for this analysis. An equal number of control plots was scattered within the same areas (for each area, the number of control plots equalled the number of territories). 61 fine-scale habitat variables (see Table 1 for list and definition of variables) were measured within 1 -ha squares $(100 \times 100 \mathrm{~m})$, following Brambilla et al. (2007a); we placed squares over territories in order to cover most of the areas defended and used by each pair. Control plots were scattered within study areas in order to occur in (i) areas not occupied by shrikes and (ii) areas with tree cover under $50 \%$ (we deliberately avoided placing control plots over areas probably unsuitable for the species because of high tree cover).

\subsubsection{Checking validity of the models}

In 2008, we mapped shrike territories in one of the 2007-study areas (Torbiere di Albate - Bassone WWF refuge), in areas including 2007-sites but enlarged as to include other open habitats (Pian di Spagna Regional Nature Reserve, northern Apennines, Valsassina; in the latter two we did not record habitat variables because of logistical constraints), and in new sites scattered over the under-studied pre-Alpine and Alpine portion of the region [Altopiano di Cariadeghe (50 ha), Alpe Rescascia (11), Livo (10), Peglio (7), Val Taleggio (37)]. The new study areas were identified on the basis of the prediction made by the habitat suitability map (Fig. 2). We made the following predictions about model validity: if our models obtained on 2007 data are adequate, (i) the new sites identified on areas predicted as highly suitable for the species should host high density of shrike territories ( $>1$ pair per 10 ha), and (ii) the occupied and unoccupied plots should be correctly classified by the fine-scale model. For the measurements of fine-scale variables at new sites, we followed the same approach described for the first study season. In total, 81 territories were considered for this analysis, and 81 control plots were scattered within the same areas (for each area, the number of control plots roughly equalled the number of territories). Fine-scale habitat variables were measured within 1 -ha squares $(100 \times 100 \mathrm{~m})$ and control plots were scattered within study areas in order to occur in (i) areas not occupied by shrikes, and (ii) areas with tree cover under $50 \%$ (we deliberately avoided placing control plots over areas probably unsuitable for the species because of high tree cover).

\section{Table 1}

Variables measured at the fine-scale level (Step 2). Amount of cover variables were recorded as percentage to the nearest $5 \%$, heights and lengths to the nearest meter.

\begin{tabular}{|c|c|}
\hline Type & Variables measured \\
\hline Topographic & Elevation, orientation, slope \\
\hline Tree layer & Area covered, minimum height, maximum height, average height \\
\hline Shrub layer & Area covered, minimum height, maximum height, average height \\
\hline Herbaceous layer & Area covered, minimum height, maximum height, average height \\
\hline Hedges & Area covered, minimum height, maximum height, average height, length of hedges \\
\hline Tree rows & Area covered, minimum height, maximum height, average height length of tree rows \\
\hline Untilled vegetation & Area covered, minimum height, maximum height, average height \\
\hline Vineyards & Area covered, minimum height, maximum height, average height \\
\hline Orchards & Area covered, minimum height, maximum height, average height \\
\hline Bare soil with scattered plants & Area covered, minimum height, maximum height, average height \\
\hline Grassland & Area covered by pastures, area covered by pastures with shrubs, area covered by dry grassland, area covered by mowed grassland \\
\hline Cultivations & Area covered by: Zea mays, wheat, other cereals, lucerne, other cultivations \\
\hline Rocky and urbanized areas & Area covered by: rocky surface and bare ground, urbanized areas, urban green areas \\
\hline Wetlands & Area covered by waterbodies, area covered by wetlands \\
\hline Unpaved roads & Area covered by unpaved roads, length of unpaved roads \\
\hline Paved roads & Area covered by paved roads, length of paved roads \\
\hline Fences & Area covered by fences, length of fences \\
\hline
\end{tabular}




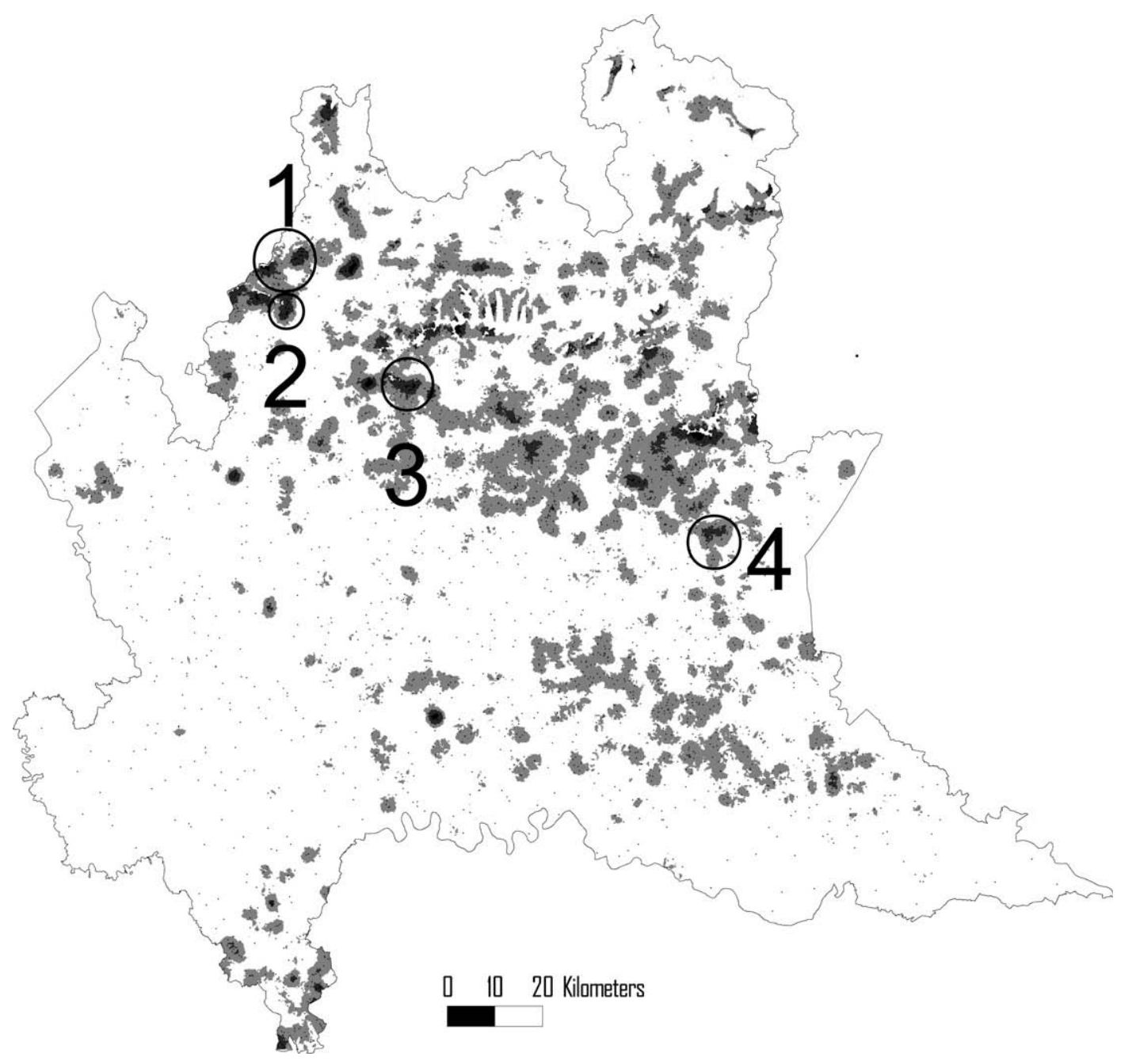

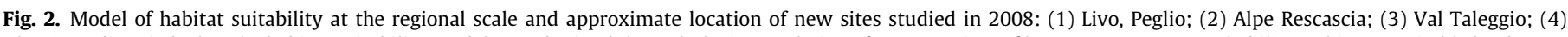

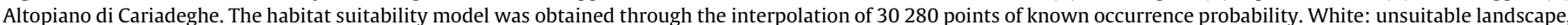

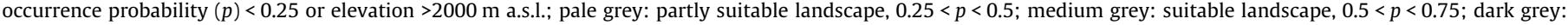
highly suitable landscape, $p>0.75$. Black dots scattered over the region indicate single sites with predicted occurrence of red-backed shrike $(p>0.5)$.

Territories where ground variables were measured in 2008 mostly came from areas not surveyed in 2007 (or from new portions of areas surveyed in both years). Only 14 out of 81 territories considered in model validation upon 2008-data were located within two areas surveyed also in the previous year (Pian di Spagna Natural Reserve and Torbiere di Albate - Bassone WWF refuge). Breeding densities (which could virtually affect habitat preferences) were comparable between years, as the number of territories found over the same areas was identical in 2007 and 2008 (eight pairs in both years in the portion surveyed both years in Pian di Spagna N.R. and six pairs in both years in the Torbiere di Albate Bassone refuge). Furthermore, also in the other study areas surveyed in both years (Valsassina, northern Apennines), breeding densities appeared very similar between 2007 and 2008. Consistently with Tryjanowski et al. (2007), apparent territory stability/ fidelity was higher in the small population of Torbiere di Albate - Bassone refuge (all territories coinciding between the 2 years), but definitely lower in the wider and more dispersed populations of Pian di Spagna, Valsassina and northern Apennines.

\subsection{Analyses}

Prior to analyses, habitat cover variables were square-root-arcsine transformed (Sokal and Rohlf, 1995); orientation (a circular variable, used in the first step) was transformed into a linear factor using a score reclassification $\left(0-30^{\circ}: 0 ; 30-60^{\circ}: 1 ; 60-90^{\circ}: 2 ; 90-\right.$ $120^{\circ}: 3 ; 120-150^{\circ}: 4 ; 150-210^{\circ}: 5 ; 210-240^{\circ}: 4 ; 240-270^{\circ}: 3$; $270-300^{\circ}: 2 ; 300-330^{\circ}: 1 ; 330-360^{\circ}: 0$ ); according to this scoring system, higher values correspond to better exposed sites, and vice versa.

We compared features of territories (circles in Step 1, squares in Step 2) with that of random (Step 1) or control (Step 2) plots by means of a $t$-test and a binary logistic regression.

2.4.1. Step 1: identifying landscape determinants of species occurrence and predicting habitat suitability at the regional scale

As we wanted the habitat model to be as general as possible, we tried to obtain a robust prediction of occurrence suitable for generalizing. To obtain a reliable and robust model, we worked out a first model on a randomly selected half of records; then, we checked model consistency over the remaining records. Model validation on a fully independent data set is the most appropriate method for validating regression models (Maggini et al., 2006).

Therefore, we randomly selected 51 territories and 51 random plots from our sample. Upon this sub-sample we compared characteristics of territories and random plots by means of a binary logistic regression analysis, using a stepwise backward procedure. Non-significant predictors ( $p>0.1$ according to the likelihood-ratio 
test) were sequentially removed from the model, until the model contained only significant terms (minimal adequate model, Crawley, 1993), whose deletion results in a significant increase of the unexplained deviance. In the regression analysis, squared terms of habitat cover variables were also tested.

The model identified by the above procedure was re-applied to the remaining 102 cases. Then, the discrimination ability of the model applied to the two complementary subsets was examined. We calculated the area under the curve of the Receiver Operating Characteristic (ROC) plots, based on a nonparametric assumption; this area provides a measure of discrimination ability, varying from 0.5 for a model with discrimination ability no better than random, to 1.0 for a model with perfect discriminatory ability (Pearce and Ferrier, 2000; Gibson et al., 2004; Rushton et al., 2004). Finally, we re-estimated the coefficient of the predictors included in the model re-calculating their values by re-applying the model to the entire dataset (102 territories and 102 random plots). In both the habitat models, data were not overdispersed (Rushton et al., 2004).

We used probability of species occurrence as an index of habitat suitability (Gibson et al., 2004). In order to extend the final habitat model over the entire regional surface, we scattered through a random procedure 30076 points within the regional boundary. Coupled with the 204 points used for model calculation, they allowed us to estimate the probability of shrikes' occurrence at 30280 points over the entire regional surface. For each random point, we created a 1-ha circle, over which the variables included in the model were measured following the same method used before for territories and random plots. Then, we applied the logistic regression model to each one of the random plots, obtaining occurrence probability for all of them. Successively, an interpolation procedure (Analysis: Kriging Interpolation, under the extension Spatial Tools 3.4 in ArcView 3.2) based on the probability of occurrence gave a map (resolution: $100 \mathrm{~m}$ ) of habitat suitability for the whole of Lombardy. From the habitat suitability map we deleted the areas located at elevation higher than $2000 \mathrm{~m}$ a.s.l., the general upper limit of species' occurrence in Italy (Brichetti and Gariboldi, 1997).

\subsubsection{Step 2: Fine-scale habitat association}

We compared characteristics of territories and random plots by means of a binary logistic regression (same procedure as above). Twenty eight variables measured only in some squares (e.g. heights of trees, which were not taken where trees were absent) were not tested in the regression model. Eighteen land-use types with proportional cover lower than $3 \%$ in both territory and random squares were not included in the analyses as too much poorly represented. Two variables (area covered by tree rows and length of tree rows) were highly intercorrelated $(r=0.89$; for all other variables $r<0.6$ ): only the one which resulted in the best singlevariable model (length of tree rows) was entered. Therefore, the following 14 variables were tested in the model: orientation, slope, elevation, area covered by trees, area covered by shrubs, length of hedges, length of tree rows, area covered by untilled vegetation, area covered by pastures, area covered by Zea mays cultivations, area covered by lucerne, length of unpaved roads, length of paved roads, length of fences. Squared terms of habitat cover variables were also presented to the model.

Also at this step, we obtained a first model on a randomly selected half of records (38 vs. 38); then, we checked model consistency over the remaining (38 vs. 38) records. Then, the discrimination ability of the model applied to the two complementary subsets was examined, using AUC of ROC plots. Finally, we reestimated the coefficient of the predictors included in the model re-calculating their values by re-applying the model to the entire dataset (76 territories and 76 random plots). In both models, standardised residuals approached a normal distribution and data were not overdispersed.

\subsubsection{Checking validity of the models}

We considered the breeding density found in the areas selected basing on habitat suitability map as a measure of model accuracy. The surface of each new study area was calculated as the potentially suitable area effectively surveyed.

We recorded habitat characteristics of territories and control plots in 2008 and classified them with the model obtained from 2007-data. Then, we estimated the discriminatory ability over the new data set by calculating the AUC of the ROC plot.

\subsubsection{Habitat determinants of breeding success}

As a measure of breeding performance, we recorded the number of fledged young at 33 territories; these territories included 27 successful pairs and six pairs known to fail reproduction. To avoid disturbance at nest, we recorded the number of fledged young by means of prolonged observations at territories. Although such an approach limits the number of data, we preferred a prudential way to measure breeding outputs to not create disturbance during breeding (to which the species is susceptible; Tryjanowski and Kuzniak, 1999) and avoided directly looking into the nest. To assess what habitat factors may affect breeding output, we carried out a Poisson regression relating the number of fledged young to habitat characteristics of territories, entering in a backward procedure the variables included in the fine-scaled model of habitat selection. This analysis was performed by means of the R software ( $R$ Development Core Team).

\subsubsection{Testing biodiversity correlates of red-backed shrike occurrence}

To test whether the presence of our study species may signal sites of high biodiversity, we measured an independent estimate of biodiversity (see e.g. Sergio et al., 2005), quantifying floral diver-

Table 2

Mean values of recorded variables for territories and random plots at landscape scale (Step 1).

\begin{tabular}{|c|c|c|c|c|}
\hline Variable & Territories $(n=102)$ & Random plots $(n=102)$ & $t$ & $p$ \\
\hline Rocky areas (\%) & $0.42 \pm 0.25$ & $4.18 \pm 1.80$ & $1.97^{\mathrm{a}}$ & 0.052 \\
\hline Shrubland (\%) & $9.75 \pm 1.95$ & $13.92 \pm 3.03$ & $0.77^{\mathrm{a}}$ & 0.422 \\
\hline Grassland (\%) & $58.44 \pm 3.68$ & $6.26 \pm 1.96$ & $-12.59^{\mathrm{a}}$ & $<0.001$ \\
\hline Woodland (\%) & $6.82 \pm 1.36$ & $14.06 \pm 2.90$ & $1.84^{\mathrm{a}}$ & 0.067 \\
\hline Urbanized (\%) & $2.71 \pm 076$ & $12.83 \pm 2.81$ & $3.07^{\mathrm{a}}$ & 0.003 \\
\hline Perennial crops (\%) & $4.29 \pm 1.53$ & $2.48 \pm 1.12$ & $-1.06^{\mathrm{a}}$ & 0.289 \\
\hline Arable land (\%) & $17.56 \pm 2.95$ & $44.76 \pm 4.24$ & $5.37^{\mathrm{a}}$ & $<0.001$ \\
\hline Waterbodies (\%) & $0.00 \pm 0.00$ & $1.50 \pm 0.68$ & $2.26^{\mathrm{a}}$ & 0.026 \\
\hline Hedges $(\mathrm{m})$ & $65.97 \pm 6.49$ & $11.94 \pm 2.56$ & -7.75 & $<0.001$ \\
\hline Elevation (m a.s.l.) & $396.15 \pm 31.95$ & $582.82 \pm 69.21$ & 2.45 & 0.016 \\
\hline Slope $\left(^{\circ}\right)$ & $5.98 \pm 0.63$ & $10.86 \pm 1.33$ & 3.31 & $<0.001$ \\
\hline Orientation $^{\mathrm{b}}$ & $2.91 \pm 0.16$ & $2.38 \pm 0.17$ & -2.23 & 0.027 \\
\hline
\end{tabular}

\footnotetext{
a Test performed on arcsin-square-root transformed variable.

b Originally circular variables transformed into score variable (see text).
} 
Table 3

Mean values of variables differing $(p<0.1)$ between shrike and control squares (fine-scale habitat variables).

\begin{tabular}{|c|c|c|c|c|}
\hline Variable & Territories $(n)$ & Control plots $(n)$ & $t$ & $P$ \\
\hline Maximum shrub height & $2.63 \pm 0.07(75)$ & $2.32 \pm 0.09(55)$ & -2.82 & 0.006 \\
\hline Average shrub height & $1.83 \pm 0.05(75)$ & $1.56 \pm 0.05(55)$ & -3.60 & $<0.001$ \\
\hline Minimum height of hedges & $0.80 \pm 0.07(51)$ & $0.63 \pm 0.07(23)$ & -1.70 & 0.098 \\
\hline Length of hedges & $72.17 \pm 8.57(76)$ & $16.91 \pm 3.82(76)$ & -5.89 & $<0.001$ \\
\hline Maximum height of tree rows & $9.69 \pm 1.02(16)$ & $12.89 \pm 1.15(9)$ & 1.99 & 0.058 \\
\hline Area covered by shrubs & $20.72 \pm 2.00(76)$ & $8.42 \pm 1.51(76)$ & $-6.53^{\mathrm{a}}$ & $<0.001$ \\
\hline Area covered by grass & $63.29 \pm 2.22(76)$ & $70.07 \pm 3.31(76)$ & $2.13^{\mathrm{a}}$ & 0.035 \\
\hline Area covered by hedges & $8.95 \pm 1.15(76)$ & $2.57 \pm 0.57(76)$ & $-5.39^{a}$ & $<0.001$ \\
\hline Area covered by untilled vegetation & $11.45 \pm 1.84(76)$ & $7.96 \pm 2.04(76)$ & $-1.83^{\mathrm{a}}$ & 0.069 \\
\hline Area covered by pastures with shrubs & $2.43 \pm 1.41(76)$ & $0.00 \pm 0.00(76)$ & $-1.74^{\mathrm{a}}$ & 0.085 \\
\hline Area covered by rocky surface and bare ground & $0.07 \pm 0.07(76)$ & $0.39 \pm 0.18(76)$ & $-1.71^{\mathrm{a}}$ & 0.091 \\
\hline
\end{tabular}

a Test performed on arcsin-square-root transformed variable.

sity in squares with and without shrikes. We counted the number of tree and shrub species within the 152 1-ha squares (76 occupied and 76 control plots) and compared average species diversity by means of a $t$-test.

\section{Results}

In 2007, red-backed shrike territories were found in all the 10 sample areas, with the number of territorial pairs ranging from 2 to 31 (agricultural landscape of low Varese province: 14; Torbiere di Albate - Bassone WWF refuge: 6; Nord Milano Regional Park: 8; northern Apennines: 31; Pian di Spagna Regional Nature Reserve: 10; Valsassina: 13; Casaletto Ceredano wildlife refuge: 8; Lanca di Gerole Regional Nature Reserve: 8; Pascoli di Crocedomini: 2; Le Bine Regional Nature Reserve: 2). Within these areas (mean sur-
To do this, we re-estimated the coefficients of the variables included in it by applying the model to the entire dataset. The model so obtained showed slightly different coefficient values:

$$
\begin{aligned}
Y= & -2.804+3.712(\text { shrubland })+3.614(\text { grassland and pastures }) \\
& +0.028 \text { (length of hedges })-2.004\left(\text { shrubland }^{2}\right)
\end{aligned}
$$

The discriminatory capacities over the entire dataset was still very high, with AUC (ROC plot) $=0.94$. The AUC of the ROC plot was equal to 0.95 and 0.93 when this final model was applied uniquely to the first or the second data subset, respectively, confirming its discriminatory ability for both the subsamples.

Therefore, we calculated for each one of the random plots scattered over the entire region the probability of shrike occurrence by means of the equation:

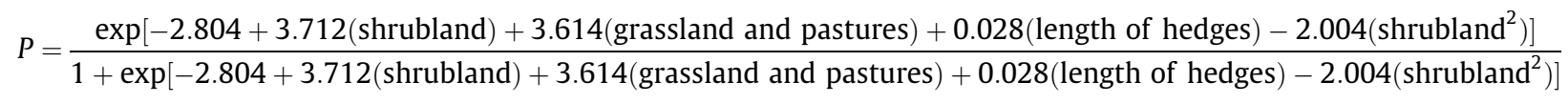

face 314 ha), density ranged between 1.2 (agricultural landscape of low Varese province, $1320 \mathrm{ha}$ ) and 18.6 (Valsassina, 70 ha) pairs per 100 ha.

Outside these 10 sample areas, 14 territories were detected in the Triangolo Lariano area and other additional 58 territories were detected over all the region (overall: 174 territories).

\subsection{Step 1: landscape model}

With respect to random plots, shrike territories were characterised by higher cover of grassland and pastures, longer length of hedges, lower cover of urbanized surface, arable land and waterbodies; moreover, they were found in sites with lower elevation and slope and better orientation than random plots (see Table 2).

The binary logistic regression model obtained over the randomly selected half of the sample (51 territories and 51 random plots) lead to the following equation:

$$
\begin{aligned}
Y= & -2.554+6.821(\text { shrubland })+3.796(\text { grassland and pastures }) \\
& +0.016(\text { length of hedges })-5.662\left(\text { shrubland }^{2}\right)
\end{aligned}
$$

This model fitted well to the dataset, with AUC (ROC plot $)=0.93$. When re-applied to the other half of the original dataset, the model still showed very good discriminatory capacity, with AUC $($ ROC plot $)=0.93$.

Therefore, we supposed that our model could be considered as sufficiently robust to be generalized to the entire regional surface.
The Kriging interpolation lead to the map showed in Fig. 2.

\subsection{Step 2: fine-scale habitat association}

With respect to control squares, shrike territories were characterised by higher maximum shrub height, higher average shrub height, longer length of hedges, lower maximum height of tree rows, greater area covered by shrubs, smaller area covered by grass and greater area covered by hedges (see Table 3 ).

The binary logistic regression model obtained over the first subset lead to the following equation:

$$
\begin{aligned}
Y= & -3.158+11.482(\text { shrubland })+6.011(\text { untilled }) \\
& +0.013(\text { length of hedges })-1.657(\text { lucerne }) \\
& -9.596\left(\text { shrubland }^{2}\right)-6.200\left(\text { untilled }^{2}\right)
\end{aligned}
$$

This had an AUC (ROC plot $)=0.87$. When re-applied to the other half of the original dataset, the model still showed good discriminatory capacity, with AUC (ROC plot) $=0.84$.

Finally, we re-estimated the coefficients of the variables by applying the model to the entire dataset:

$$
\begin{aligned}
Y= & -2.689+9.580(\text { shrubland })+4.151(\text { untilled }) \\
& +0.014(\text { length of hedges })-1.765(\text { lucerne }) \\
& -7.101\left(\text { shrubland }^{2}\right)-4.350\left(\text { untilled }^{2}\right)
\end{aligned}
$$


The discriminatory capacity over the entire dataset was still very high, with AUC (ROC plot) $=0.86$. The AUC of the ROC plot was equal to 0.87 and 0.84 when this final model was applied uniquely to the first or the second data subset, respectively, confirming its discriminatory ability for both the subsamples.

\subsection{Checking validity of the models}

The areas selected on the portions of the regional surface depicted as highly suitable by the interpolation model host a high breeding density of the species, ranging from 4 (Altopiano di Cariadeghe) to 10 pairs (Livo) per 10 ha ( $N=5$, areas ranging from 7 to 50 ha).

The fine-scale habitat model applied to the 2008 dataset (81 territories and 81 control squares) showed a very high explanatory power, with AUC of the ROC plot equal to $0.88 \pm 0.03$.

\subsection{Habitat determinants of breeding success}

None of the habitat variables tested in the Poisson regression model (shrubland and its squared-value, untilled and its squaredvalue, length of hedges, lucerne) affected the number of fledged young (for all factors, at removal from the model $p \geqslant 0.14$ ).

\subsection{Biodiversity correlates of red-backed shrike occurrence}

The number of shrub species was definitely higher at occupied rather than at control squares $(5.39 \pm 0.29$ vs. $3.04 \pm 0.35, t=-1.44$, $p<0.001$ ), while the number of tree species was marginally higher at shrike squares $(2.97 \pm 0.22$ vs. $2.49 \pm 0.25, t=-5.15, p=0.151)$.

\section{Discussion}

\subsection{Models obtained at different levels have different application}

Both the habitat models we obtained, at landscape- and territory-level, appear to be useful for shrike conservation in Lombardy, but with really different target. The GIS-model produced a map of suitable habitat which helped us in identifying previously unknown areas of great importance for the species, especially in the under-studied Alpine and pre-Alpine portions of the region: the sites predicted as highly suitable from the GIS map hosted large populations of the species, breeding at high density. Therefore, the coarse-scale model really help conservationists in identifying important areas for the species and the habitat suitability map produced can facilitate decision about the protection, increment or restoration of shrike habitats and can point out need for connection among isolated habitat patches and/or populations. Given the rather limited extent of both grassland and shrubland patches in Lombardy (with the exception of Alpine and pre-Alpine areas), an average probability of $0.25-0.5$ almost invariably indicates the occurrence of suitable patches interspersed within a less suitable landscape matrix (e.g. grassland with hedges within primarily cultivated areas). The graphical representation of nearly 3300 suitable sites (see Fig. 2) allows conservationists and managers to identify also potential sites outside largely suitable landscapes: by looking at the map, it clearly stands out how many sites predicted as occupied by the species occur even within the unsuitable matrix.

However, the information provided by the GIS-model are not sufficiently detailed for drawing site-level conservation measures. Apart from the association with intermediate shrub cover and the positive effect of hedgerow length, which were correctly identified, this model failed in pointing out the importance of intermediate cover of untilled land and the negative effect of lucerne cover (two variables not available among GIS data layers) and probably overestimated the importance of grassland habitats. More in general, a species' ecology may be affected also by factors different from land-uses and hardly available as GIS layers, including e.g. food availability, microclimatic features, predator occurrence, and disturbance.

Analyses at site level, using fine-scale habitat variables, have been encouraged to gain more insight into ecological needs of target organisms (Gibson et al., 2004); in our study, we were able to get an insight into detailed ecological needs of the species by means of analyses based on ground-measured variables, which revealed detailed habitat preferences of the species, providing with knowledge needed for conservation through habitat management. On the other hand, the fine-scale model could not be extrapolated to wide areas, as it is dependent on the ground-measurements of detailed vegetation variables, and thus its applicability is limited to areas where variables are readily measurable on ground. Moreover, the site-level analysis could not reflect the strong association with grasslands showed by shrikes at landscape level, as territories and control areas considered in the second step of the work were both in open (i.e. mainly grasslands) areas.

The combination of the two models, i.e. the GIS-based one and the other derived from measurement of detailed on-ground variables, could provide with an effective account of habitat preferences, able to display the distribution of suitable habitats at landscape level, and to indicate detailed ecological requirements of a species at territory level.

\subsection{Red-backed shrike status and habitat preferences in Lombardy}

We detected a considerable number of shrike territories (174 in 2007 and 241 in 2008), confirming that the species still has important populations in the region, despite recent population crashes (Cairo et al., 2003; Gagliardi et al., 2007). Moreover, the locally very high breeding density (from 4 to 10 pairs per 10 ha in the areas identified on the basis of the prediction made by the model of habitat suitability and mapped in 2008) confirmed the occurrence of dense populations. However, given the steep decline undergone by red-backed shrike over most of Lombardy (and more in general over most of Europe), urgent measures should be undertaken for its conservation. Actions aiming at promoting shrike conservation through habitat management should be beneficial also to other taxa, as suggested by biodiversity correlates of shrike occurrence, which indicate higher floral diversity at shrike territory. The habitat structure characterising shrike territories (mowed or grazed grasslands with partial shrub cover, hedgerow occurrence, small areas of untilled surfaces) can be suitable to a large number of species, both of birds (Tucker and Evans, 1997) and other taxa (Pykala, 2003). In particular, many other species of high conservation importance show similar habitat preferences in Lombardy and nearby areas, including buntings (Negri et al., 2005; Brambilla et al., 2008, 2009) and warblers (Brambilla et al., 2007b).

Both the habitat models we identified confirmed previous findings of different studies, i.e. the need for shrub and pastures/grasslands (Vanhinsbergh and Evans, 2002; Golawski and Meissner, 2008) and for hedges (Brambilla et al., 2007a). Moreover, the association of the species with partial shrub cover as outlined at both scales confirmed the effect reported by Vanhinsbergh and Evans (2002) in Austria, and hypothesized by Brambilla et al. (2007a) for an extra-regional Apennine sector.

Our models were built upon data representative of the regional diversity and range of conditions inhabited by the species. They were identified and then tested upon two independent datasets, and proved to fit well and with nearly identical discriminatory performance to both. The validation procedure carried out with 2008data definitely confirmed their strength. Therefore, we can be rather confident that our models (i) identified truly important hab- 
itat factors, and (ii) could have a certain degree of generality over the region.

Some differences with respect to results of previous works have to be pointed out; in the above cited extra-regional Apennine sector, characterised by low-intensity farming, the type of herbaceous vegetation did not affect shrike occurrence (Brambilla et al., 2007a), while in this study the species clearly appears to select mowed or grazed grassland. This is probably because the other study (Brambilla et al., 2007a) took place in low-farming landscapes, while cultivations in Lombardy are predominantly under intensive regimes, which are usually associated with lower ecological quality of arable lands and other habitats (Evans et al., 1997; Brambilla et al., 2008).

Intensification of farming practices is even more likely to severely affect habitat occurrence and quality if considering the outcomes of our study. In recent decades hedges have been reduced and shrub patches wiped out over most cultivated areas of Lombardy, in order to maximize the arable surface. Also grasslands, once widespread in the region, are currently undergoing a great reduction, especially in lowland areas, because of dairy herds decreasing, and are often substituted by maize fields. Similarly, pastures have been often converted into other land-use types, as livestock rearing is becoming more and more intensive.

On the other hand, the occurrence of grassland and pastures, as well as of partial cover of shrubland, is seriously compromised also by land-use abandonment; abandoned pastures and fields are progressively covered by unsuitable dense vegetation of shrubs and trees.

A rather encouraging finding of our work is that some Natura 2000 sites (SCIs and SPAs) and other protected areas (see Section 3 ) host healthy populations of the species; here, suitable management practices should be easily adopted and unfavourable changes of land-use prevented.

As it is vulnerable to unsuitable habitat changes, the redbacked shrike does positively respond to dedicated actions of habitat management. There are some examples of population recovery following specific conservation measures, both in Italy (see Casale et al., 2007) and elsewhere (e.g. in Switzerland). Also in Lombardy, the newly created shrubland patches close to mown grassland in the Nord Milano Regional Park provided the species with suitable nesting places and allowed the existence of a shrike population at the edge of Milan. Therefore, suitable habitat management may allow conservation (or even recovery) of the currently declining population of red-backed shrike in Lombardy.

\subsection{Conservation implications at regional- and site-level}

Main conservation measures at landscape level should involve the maintenance/promotion of grassland habitats (see also Golawski and Meissner, 2008) and hedges with shrubs. This could be achieved by adequate use of agricultural subsidies, specific projects of habitat conservation funded by EU, protected areas, provinces or regional government, and through adequate habitat management and restoration based on, for example, the regionally common compensation/mitigation funds.

Sites predicted as occupied by the species occur even within the unsuitable matrix. In the western sector and in the south-eastern 'corner', the density of suitable sites is lower than in other parts: the former includes the most urbanized area (central-northern portion) and wide extensions of rice cultivations (western 'corner'), while the latter includes the area with most intensive and mechanized agriculture, where the few suitable sites are associated with residual hedges and scattered grassland, or with shrub patches close to natural grassland within (or in proximity to) the flood plain of the Po river.
Maintaining large and continuous extents of suitable habitats at landscape scale is particularly important in large areas with high population density, also in relation to the reported site infidelity at such a scale in dense populations (Tryjanowski et al., 2007).

At site level, results confirmed the association with higher length of hedges and with partial shrub cover, and further outlined an association with partial cover of untilled (herbaceous) vegetation and a negative effect of the cover of lucerne on the probability of species occurrence. The effect of untilled grassland on shrike occurrence has been already reported by Casale et al. (2007) on the basis of qualitative evidence of the favourable effect of maintaining untilled areas at the edge of mowed grasslands; now, we provide with a quantitative assessment of the beneficial effect of partial cover of untilled areas.

Therefore, according to the average characteristics of favoured habitats in the study area, a shrike territory should comprise approximately 55-65\% of grassland (with preference for lowintensity pasture and mowed grassland), 15-35\% of shrubs and $5-20 \%$ of untilled herbaceous vegetation, and include some hedges (average length for territories $72 \mathrm{~m}$; $66 \mathrm{~m}$ according to the landscape model).

Determinants of breeding success require further investigation and probably also an even larger dataset (cf. Golawski and Meissner, 2008; Golawski, 2008). The habitat traits important in discriminating between occupied and unoccupied areas apparently have no clear effect on breeding performances. Other factors, such as rainfall and other climatic values (Fornasari and Massa, 2000; Golawski, 2006), predator occurrence and proximity (Fornasari and Massa, 2000; Roos and Pärt, 2004), nest site (Tryjanowski et al., 2000), food availability (Golawski and Meissner, 2008) or human disturbance, may have an important role in affecting the number of offspring.

\section{Acknowledgments}

We are very grateful to the editors R. Primack and N. Sodhi and, especially, to two anonymous reviewers who provided helpful comments on a previous version of the manuscript. The study has been funded to MB, FC and PS by Fondazione Lombardia per l'Ambiente (FLA). The Environmental Department (DGQA) of Lombardy Region funded further investigation to FLA. We are very grateful to F. Piccarolo, G. Bottari, F. Picco, G. Ferrario, R. Gini for kind availability and cooperation; to R. Brembilla, S. Ravara, M. Siliprandi and F. Cecere for working in some of the intensive sample areas; to M. Barattieri, E. Bassi, G. Bazzi, R. Bionda, M. Caffi, N. Canovi, S. Capelli, P. Casali, J. Cecere, S. Colaone, G. Conca, O. Cortesi, G. de Martini, E. de Sanctis, C. dell'Acqua, B. Fanchin, F. Ferlini, A. Garanzini, E. Giussani, M. Gobbini, W. Guenzani, S. Landoni, G. Luraschi, E. Manfredini, L. Marocchi, D. Massalongo, G. Meraviglia, F. Mogavero, A. Mosini, L. Mostini, C. Movalli, A. Nava, F. Ornaghi, G. Papale, G. Pasquariello, G. Piazzi, S. Pirola, S. Ravara, L. Ravizza, R. Repossini, R. Sala, R. Santinelli, F. Saporetti, W. Sassi, C. Scandolara, V. Toninelli, A. Turri, U. Visconti, T. Zarbo for searching for shrikes outside the study areas; to F. Ficetola, L. Fornasari, A. Gagliardi, A. Martinoli, D. Preatoni, S. Sonno, G. Tellini Florenzano, L. Wauters for helping in other ways. N. Sills greatly improved a previous version of the ms.

\section{References}

Austin, M.P., 2002. Spatial prediction of species distribution: an interface between ecological theory and statistical modelling. Ecological Modelling 157, $101-118$

Benton, T.G., Vickery, J.A., Wilson, J.D., 2003. Farmland biodiversity: is habitat heterogeneity the key? Trends in Ecology and Evolution 18, 182-188.

BirdLife International, 2004. Birds in the European Union: A Status Assessment. BirdLife International, Wageningen. 
Bogliani, G., Cova, C., Polani, F., 2003. La natura tra Nure e Scrivia. Il Territorio del Giardino di Pietra Corva. Provincia di Pavia, Pavia.

Brambilla, M., Rubolini, D., 2009. Intra-seasonal changes in distribution and habitat associations of a multi-brooded bird species: implications for conservation planning. Animal Conservation 12, 71-77.

Brambilla, M., Rubolini, D., Guidali, F., 2007a. Between land abandonment and agricultural intensification: habitat preferences of red-backed shrikes Lanius collurio in low-intensity farming conditions. Bird Study 54, 160-167.

Brambilla, M., Reginato, F., Guidali, F., 2007b. Habitat use by Moltoni's Warbler Sylvia cantillans moltonii in Italy. Ornis Fennica 84, 91-96.

Brambilla, M., Guidali, F., Negri, I., 2008. The importance of an agricultural mosaic for Cirl Buntings Emberiza cirlus in Italy. Ibis 150, 628-632.

Brambilla M., Guidali, F., Negri, I., 2009. Breeding-season habitat associations of the declining Corn Bunting Emberiza calandra - a potential indicator of the overall bunting richness. Ornis Fennica 84, in press.

Brichetti, P., Gariboldi, A., 1997. Manuale Pratico di Ornitologia. Edagricole Calderini, Bologna.

Cairo, E., Ferrario, E., Bassi, E., Caccia, M., Rota, R., 2003. L'avifauna della provincia di Bergamo: check-list aggiornata al 2001 e caratterizzazione fenologica. Rivista del Museo Civico di Scienze Naturali “E Caffi” Bergamo 21, 47-85.

Casale, F., Bionda, R., Falco, R., Siccardi, P., Toninelli, V., Rubolini, D., Brambilla, M., 2007. Misure gestionali in campo agro-pastorale per la conservazione dell'averla piccola Lanius collurio. Atti del XIV Convegno Italiano di Ornitologia, Trieste.

Crawley, M.J., 1993. GLIM for Ecologists. Blackwell Scientific Publications, Oxford.

Ellenberg, H., 1986. Warum gehen die Neuntöter (Lanius collurio) in Mitteleuropa in Bestand zurück. Corax 12, 34-46.

Evans, A.D., Smith, K.W., Buckingham, D.L., Evans, J., 1997. Seasonal performance and nestling diet of Cirl Buntings Emberiza cirlus in England. Bird Study 44, 6679.

Favreau, J.M., Drew, C.A., Hess, G.R., Rubino, M.J., Koch, F.H., Eschelbach, K.A., 2006. Recommendations for assessing the effectiveness of surrogate species approaches. Biodiversity and Conservation 15, 3949-3969.

Fornasari, L., Massa, R., 2000. Habitat or climate? Influences of environmental factors on the breeding success of the red-backed shrike (Lanius collurio). Ring $22,147-156$.

Fornasari, L., Kurlavicius, P., Massa, R., 1997. Lanius collurio red-backed strike. In: Hagemeijer, E.J.M., Blair, M.J. (Eds.), The EBCC Atlas of European Breeding Birds: Their Distribution and Abundance. T\&AD Poyser, London, pp. 660-661.

Fuller, R.J., Gregory, R.D., Gibbons, D.W., Marchant, J.H., Wilson, J.D., Carter, N., 1995. Population declines and range contractions among lowland farmland birds in Britain. Conservation Biology 9, 1425-1441.

Gagliardi, A., Guenzani, W., Preatoni, D.G., Saporetti, F., Tosi, G., 2007. Atlante Ornitologico Georeferenziato della provincia di Varese. Uccelli nidificanti 20032005. Provincia di Varese, Civico Museo Insubrico di Storia Naturale di Induno Olona, Università degli Studi dell'Insubria sede di Varese.

Gibson, L.A., Wilson, B.A., Cahill, D.M., Hill, J., 2004. Spatial prediction of rufous bristlebird habitat in a coastal heathland: a GIS-based approach. Journal of Applied Ecology 41, 213-223.

Golawski, A., 2006. Impact of weather on partial loss of nestlings in the red-backed shrike Lanius collurio in eastern Poland. Acta Ornithologica 41, 15-20.

Golawski, A., 2008. No evidence of weather effect found on the clutch size, eggs size and their hatchability in the red-backed shrike Lanius collurio in eastern Poland. Annales Zoologici Fennici 45, 513-520.

Golawski, A., Golawska, S., 2008. Habitat preference in territories of the red-backed shrike Lanius collurio and their food richness in an extensive agriculture landscape. Acta Zoologica Academiae Scientiarum Hungarica 54, 89-97.

Golawski, A., Meissner, W., 2008. The influence of territory characteristics and food supply on the breeding performance of the red-backed shrike (Lanius collurio) in an extensively farmed region of eastern Poland. Ecological Research 23, 347353.

Guenzani, W., Saporetti, F., 1988. Atlante degli Uccelli Nidificanti in Provincia di Varese. Edizioni Lativa, Varese.

Guisan, A., Zimmermann, N.E., 2000. Predictive habitat distribution models in ecology. Ecological Modelling 135, 147-186.

Hall, L.S., Mannan, R.W., 1999. Multiscaled habitat selection by elegant trogons in southeastern Arizona. Journal of Wildlife Management 63, 451-461.

Jaberg, C., Guisan, A., 2001. Modelling the distribution of bats in relation to landscape structure in a temperate mountain environment. Journal of Applied Ecology 38, 1169-1181.

Karlsson, S., 2004. Season-dependent diet composition and habitat use of redbacked shrikes Lanius collurio in SW Finland. Ornis Fennica 81, 97-108.

Krebs, J.R. et al., 1999. The second silent spring? Nature 400, 611-612.
Kuzniak, S., Tryjanowski, P., 2000. Distribution and breeding habitat of the redbacked shrike (Lanius collurio) in an intensively used farmland. Ring 22, 89-93.

Lindenmayer, D.B., Cunningham, R.B., McCarthy, M.A., 1999. The conservation of arboreal marsupials in the montane ash forests of the central highlands of Victoria, south-eastern Australia. VIII. Landscape analysis of the occurrence of arboreal marsupials. Biological Conservation 89, 83-92.

Loyn, R.H., McNabb, E.G., Volodina, L., Willig, R., 2001. Modelling landscape distributions of large forest owls as applied to managing forests in north-east Victoria, Australia. Biological Conservation 97, 361-376.

Luck, G.W., 2002. The habitat requirements of the rufous treecreeper (Climacteris rufa). I. Preferential habitat use demonstrated at multiple spatial scales. Biological Conservation 105, 383-394.

Maggini, R., Lehmann, A., Zimmermann, N.E., Guisan, A., 2006. Improving generalized regression analysis for the spatial prediction of forest communities. Journal of Biogeography 33, 1729-1749.

Manel, S., Dias, J.M., Buckton, S.T., Ormerod, S.J., 1999. Alternative methods for predicting species distribution: an illustration with Himalayan river birds. Journal of Applied Ecology 36, 734-747.

Maréchal, P., 1993. Over externe factoren die de habitatkvhwaliteit van de Grauwe Klauwier Lanius collurio beinvloeden. Vogeljaar 41, 34-48.

Negri, I., Brambilla, M., Guidali, F., 2005. Abbondanza degli zigoli (Emberizidae) in relazione all'uso del suolo nell'Appennino settentrionale. Avocetta 29, 95.

Osborne, P.E., Alonso, J.C., Bryant, R.G., 2001. Modelling landscape-scale habitat use using GIS and remote sensing: a case study with great bustards. Journal of Applied Ecology 38, 458-471.

Peach, W., Baillie, S., Underhill, L, 1991. Survival of British Sedge Warblers Acrocephalus schoenobaenus in relation to west African rainfall. Ibis 133, 300-305.

Pearce, J., Ferrier, S., 2000. Evaluating the predictive performance of habitat models developed using logistic regression. Ecological Modelling 133, 225-245.

Pykala, J., 2003. Effects of restoration with cattle grazing on plant species composition and richness of semi-natural grasslands. Biodiversity and Conservation 12, 2211-2226.

Roos, S., Pärt, T., 2004. Nest predators affect spatial dynamics of breeding redbacked shrikes (Lanius collurio). Journal of Animal Ecology 73, 117-127.

Rushton, S.P., Ormerod, S.J., Kerby, G., 2004. New paradigms for modelling species distributions? Journal of Applied Ecology 41, 193-200.

Saino, N., Szép, T., Romano, M., Rubolini, D., Spina, F., Møller, A.P., 2004. Ecological conditions during winter predict arrival date at the breeding quarters in a transSaharan migratory bird. Ecology Letters 7, 21-25.

Sergio, F., Marchesi, L., Pedrini, P., 2004. Integrating individual habitat choices and regional distribution of a biodiversity indicator and top predator. Journal of Biogeography 31, 619-628.

Sergio, F., Newton, I., Marchesi, L., 2005. Top predators and biodiversity. Nature 436, 192.

Siriwardena, G.M. et al., 1998. Trends in the abundance of farmland birds: a quantitative comparison of smoothed common birds census indices. Journal of Applied Ecology 35, 24-43.

Suárez-Seoane, S., Osborne, P.E., Baudry, J., 2002. Responses of birds of different biogeographic origins and habitat requirements to agricultural land abandonment in northern Spain. Biological Conservation 105, 333-344.

Titeux, N., Dufreneb, M., Radouxc, J., Hirzeld, A.H., Defournyc, P., 2007. Fitnessrelated parameters improve presence-only distribution modelling for conservation practice: the case of the red-backed shrike. Biological Conservation 138, 207-223.

Tryjanowski, P., Golawski, A., 2004. Sex differences in nest defence by the redbacked shrike Lanius collurio: effects of offspring age, brood size, and stage of breeding season. Journal of Ethology 22, 13-16.

Tryjanowski, P., Kuzniak, S., 1999. Effect of research activity on the success of redbacked shrike Lanius collurio nests. Ornis Fennica 76, 41-43.

Tryjanowski, P., Kuzniak, S., Diehl, B., 2000. Breeding success of the red-backed shrike (Lanius collurio) in relation to nest site. Ornis Fennica 77, 137-141.

Tryjanowski, P., Sparks, T.H., Crick, H.Q.P., 2006. Red-backed shrike (Lanius collurio) nest performance in a declining British population: a comparison with a stable population in Poland. Ornis Fennica 83, 181-186.

Tryjanowski, P., Golawski, A., Kuzniak, S., Mokwa, T., Antczak, M., 2007. Disperse or stay? Exceptionally high breeding-site infidelity in the red-backed shrike Lanius collurio. Ardea 95, 316-320.

Tucker, G.M., Evans, M.I., 1997. Habitats for Birds in Europe: A Conservation Strategy for the Wider Environment. BirdLife International, Cambridge.

Tucker, G.M., Heath, M.F., 1994. Birds in Europe: Their Conservation Status. BirdLife International, Cambridge.

Vanhinsbergh, D., Evans, A., 2002. Habitat associations of the red-backed shrike (Lanius collurio) in Carinthia, Austria. Journal of Ornithology 143, 405-415. 